INVESTIGACIÓN

\title{
La educación del siglo XXI en tiempos de pandemia
}

Linne, Joaquín*

\section{Resumen}

Este artículo indaga en las prácticas en escuelas secundarias durante la pandemia de COVID. Para esto, se realizó una encuesta (n: 623) y entrevistas a cuarenta estudiantes y docentes de Buenos Aires. En los resultados, se evidencian las tensiones producidas, desde las dificultades de equipamiento y conectividad en escuelas con mayor población de sectores populares hasta ansiedad y depresión en estudiantes y burnout en docentes, padres y madres. Más allá de las dificultades y la incertidumbre, los estudiantes valoran el esfuerzo docente y extrañan asistir a la escuela como espacio de encuentro y sociabilidad. También demandan una actualización de contenidos y una mayor inclusión de conocimiento informático que les sea útil. Entre las conclusiones, se sostiene que la escuela articula coordenadas fundamentales en torno a la construcción ciudadana, más allá de cierto desfasaje con ciertas prácticas culturales que predominan en el siglo XXI.

Palabras clave: educación; pandemia; tecnologías digitales; jóvenes

Este artículo se inserta dentro de la producción del grupo de investigación «Tiempo de definiciones. Experiencia educativa, ciudadanía y cultura digital en la escuela secundaria y la educación superior», con sede en Flacso Argentina y dirigido por Pedro Núñez. Pertenezco al grupo responsable del proyecto, que es financiado por la Agencia FONCyT. Recibido el 21/12/2020, aceptado el 01/06/2021 y publicado el 27/07/2021.

DOI: https://doi.org/10.33255/3262/977

Autoría: ${ }^{\star}$ Conicet (Argentina).

Contacto: joaquinlinne@gmail.com 


\title{
21st century education in times of pandemic
}

\begin{abstract}
This paper explores high school internships during the COVID pandemic. For this, a survey (n: 623) and interviews with 40 students and teachers from Buenos Aires were carried out. Among the results, the tensions produced are evident, from the difficulties of equipment and connectivity in schools with a larger population of popular sectors, to anxiety and depression in students and burn out in teachers, parents. Beyond difficulties and uncertainties, students value teaching effort and miss attending school as a space for meeting and sociability. They also demand an update of content and a greater inclusion of computer knowledge that is useful to them. Among the conclusions, it is argued that the school articulates fundamental coordinates around the construction of citizenship, beyond a certain gap with certain cultural practices that predominate in the 21st century.
\end{abstract}

Keywords: education; pandemic; digital technologies; youth

\section{A educação do século XXI em tempos de pandemia}

\section{Resumo}

Este artigo explora os estágios do ensino médio durante a pandemia COVID. Para isso, foi realizada uma pesquisa ( $n: 623$ ) e entrevistas com 40 alunos e professores de Buenos Aires. Dentre os resultados, ficam evidentes as tensões produzidas, desde as dificuldades de equipamentos e conectividade em escolas com maior população de setores populares, até ansiedade e depressão em alguns alunos e estresse e desgaste em grande parte dos professores, assim como nos pais. e mães. Centros de estudantes, cooperadores e professores tentaram aliviar o orçamento limitado e a falta de recursos. Para além da incerteza, os alunos valorizam o esforço docente e a saudade da escola como espaço de encontro, debate e convivência. Eles também exigem uma atualização de conteúdo e maior inclusão de computação útil. Entre as conclusões, argumenta-se que a escola articula coordenadas fundamentais em torno da construção da cidadania.

Palavras-chave: educação; pandemia; tecnologias digitais; juventude 


\section{Introducción}

Niños $\underline{1}$ que interrumpen sus clases por videollamada porque les suena el celular, ruidos molestos de estudiantes que no tapan sus audios, madres y padres quejándose a docentes y autoridades de que no les dan suficientes clases sincrónicas, o discutiendo entre sí porque sus hijos molestan en los encuentros online, clases de actividad física con música tan alta que tapa las palabras de quien coordina, inconvenientes técnicos y de logística, problemas con internet, dificultad para motivar a los estudiantes tanto desde las pantallas como en los hogares.

Millones de niños y adolescentes a lo largo del planeta están encerrados en sus casas, jugando videojuegos en sus habitaciones, mirando televisión y YouTube, consultando tutoriales, escuchando música, chateando y conversando con amistades y a veces con desconocidos. Casi siempre presionados por sus padres, realizan las tareas escolares y las envían por WhatsApp, e-mail, alguna plataforma o red social. La era del colegio ambulante. «Ahora es mi medio de comunicación y de estudio, así que no me pueden sacar la compu ni el celu», dicen numerosos niños y adolescentes.

Este trabajo indaga en los desafíos que implica para el sistema educativo la pandemia del COVID-19. El contexto de indagación se enmarca en los primeros meses de la pandemia y cuarentena en Argentina, desde abril hasta septiembre de 2020. En paralelo a la revisión del estado del arte, con el grupo de investigación «Tiempo de definiciones. Experiencia educativa, ciudadanía y cultura digital en la escuela secundaria y la educación superior», durante la pandemia COVID-19 realizamos entrevistas a estudiantes y docentes (n: 40) y una encuesta (n: 623) con un cuestionario autoadministrado de modo online a estudiantes de colegios secundarios de la Ciudad de Buenos Aires. Las preguntas fueron redactadas mediante reuniones virtuales del grupo de investigación en base a la experiencia docente de los miembros del grupo y a las primeras entrevistas en profundidad realizadas a docentes y estudiantes. El cuestionario se encontró disponible en una página web de junio a agosto de 2020 y fue difundido vía redes sociales con el método «bola de nieve». Un tercio de la muestra pertenece a escuelas privadas, un tercio a escuelas preuniversitarias (Nacional Buenos Aires, Pellegrini, Ilse, Lenguas Vivas) y un tercio a escuelas públicas no universitarias (Fader, Raggio, Normal 1, Liceo 9, etc.). Más allá de la coyuntura, que profundiza la tendencia a la educación a distancia, la pregunta sigue siendo la misma: en una sociedad desigual y crecientemente tecnologizada, ¿cómo integrar las tecnologías digitales a las currículas? Además, dado que el teléfono móvil se ha convertido en la primera pantalla, ¿cómo utilizarlo 
con mayor eficiencia y creatividad en las tareas educativas? ¿De qué modos generar aprendizaje significativo en el siglo XXI?

\section{El eterno dilema de las tecnologías en la escuela}

Desde inicios del siglo XXI, las ciencias sociales vienen reflexionando sobre la inclusión de las tecnologías digitales en las aulas. Entre los discursos más exaltados de apocalípticos o integrados, algunos buscan una posición intermedia. Hace ya más de diez años, Silvina Gvirtz y Marina Larrondo (2007) aconsejaban incrementar el trabajo colaborativo, dejando de premiar el logro individual. Ese mismo año, Nicholas Burbules (2007) planteaba que para los docentes es más fácil incorporar las tecnologías dígito-conectivas que los estudiantes ya poseen y manipulan. Dado que el teléfono es de uso casi universal, y permite grabar audio y video, sacar y editar fotos, escribir, leer y editar textos, nadie puede negar que se ha convertido en una herramienta de información y aprendizaje. Burbules también señalaba que el aprendizaje ubicuo, al permitir ser realizado en cualquier lugar y momento, habilita que los eventos cotidianos incluyan instancias educativas. Sin embargo, como puede observarse en el informe de la evaluación Aprender de 2016, los usos educativos de la tecnología resultan limitados:

La búsqueda de información en internet, la lectura y producción de textos digitales y el trabajo colaborativo con pares son actividades que se realizan más asiduamente en las aulas cuando se utilizan computadoras. Por el contrario, el empleo de simuladores, videojuegos educativos y redes sociales, así como también la programación informática, son tipos de uso menos habituales.

(Tófalo, 2017: 44)

Según el informe mencionado, el $50 \%$ advierte que solo a veces aprende más con el uso de la computadora. Es decir, la mitad de las veces ocurre algo (dispersión, inconvenientes, dificultades técnicas, falta de tareas claras) que hace que usar la computadora sea menos productivo que aprender de manera analógica y «tradicional». En esta línea, Inés Dussel (2017) advierte que la retórica de inevitabilidad de las tecnologías digitales sobre la educación no habilita una reflexión productiva sobre cómo introducirlas de modos que sean positivos para los estudiantes. De no mediar una reflexión que incluya a los distintos actores de la comunidad educativa, el riesgo es que la tecnologización devenga en un proceso pedagógico más automatizado, con respuestas estandarizadas y una atención más difusa. 
Hasta la pandemia, una de las principales tensiones en el ámbito educativo era la proliferación del teléfono móvil en las aulas. Esta supercomputadora de bolsillo que los estudiantes suelen manejar con mayor destreza y naturalidad que los docentes genera múltiples tensiones en el vínculo pedagógico, así como suele perturbar el desarrollo de la clase.

El celular aparece como amenazante porque, además de alterar los modelos de comunicación escolar, es un puente directo e instantáneo con el mundo exterior. No olvidemos que el celular puede grabar y registrar imágenes. Así, llega aún más lejos: permite llevar a la propia escuela al exterior. El uso del celular genera sus propios códigos escritos y orales en niños y jóvenes. (Gvirtz y Larrondo, 2007: 5)

Si bien el principal uso de los teléfonos en estos entornos es la búsqueda de información, también funcionan como ansiolítico digital para quienes tienen dificultades con el estudio. Cuando su uso se circunscribía al aula, algunos docentes lo permitían siempre que no perturbara el desarrollo de la clase. En efecto, la mayoría de docentes y estudiantes han acordado una nueva norma de etiqueta, similar a la de muchos hogares: utilizar el celular mientras no molesten al resto.

Ahora depende más de la accesibilidad a las tecnologías, los que tienen una compu con internet y los que no. Pero antes de la pandemia lo que pasaba es que, si no te interesaba la materia y no prestabas atención, te podías quedar con el celular tranquilo con tal de que no hablaras y no molestaras. (Estudiante, 17, escuela pública)

Este uso omnipresente e hipnótico de los teléfonos, con sus múltiples opciones atractivas, su multitasking y sus notificaciones constantes, ha terminado por invadir el tiempo educativo -y no solo el educativo-, que termina en jornadas más extensas e interrumpidas. Algo parecido ocurre con lo laboral, sobre todo en el expandido work home o teletrabajo: una tarea que antes podía ser resuelta en pocas horas ahora es dilatada pues se entrecruza con las procastinadoras actividades de ocio: chat, música, juegos, redes sociales, porno, streaming de videos, comercio digital y consumos culturales.

De acuerdo a una encuesta realizada a estudiantes, Sebastián Benítez Larghi (2020) señala que el $70 \%$ no puede llegar a cuarenta minutos continuos de concentración en un texto, más de la mitad no logra hacerlo por veinte minutos y un $25 \%$ no consigue concentrarse por más de cinco minutos en una sola tarea. Esta condición de frenético multitasking que promueven las 
principales plataformas digitales resulta difícil de ser compatibilizada con la lógica escolar basada en la focalización en un solo tema y en un único estímulo. El autor advierte sobre las afinidades electivas que tiene el multitasking con el capitalismo contemporáneo, que busca empleados dóciles, flexibles y fácilmente adaptables.

Se torna evidente que tanto directivos como docentes y estudiantes enfrentan múltiples desafíos. En este contexto, surge la propuesta de la gamificación, que consiste en introducir elementos lúdicos en el proceso educativo. Moda o tendencia, una parte del estado del arte asegura que, bajo ciertas condiciones como acompañamiento docente y equipamiento tecnológico adecuado, la gamificación mejora el rendimiento académico al incrementar la motivación, predisposición, atención e integración, así como permite el uso de recursos novedosos y el estímulo de roles más activos y emociones positivas en los estudiantes (Holguín et al., 2020; Ortiz-Colón et al., 2018, y Hernández-Horta et al., 2018). Otra propuesta didáctica es la estrategia del aula invertida (flipped classroom), que tiene como propósito dejar lectura, explicación teórica e investigación para el hogar, incrementando el diálogo y el trabajo grupal en el aula. Para esto, Sergio Zepeda-Hernández et al. (2016) señalan que se preparan actividades prácticas que desarrollen actividades de aprendizaje significativo. De esta forma, al terminar cada clase, se presenta el próximo tema, especificando que al inicio de la siguiente clase se realizarán actividades para obtener puntos en función de conocimientos adquiridos. Los autores sostienen que, sin presionar ni mencionar la palabra «tarea», los estudiantes realizan lecturas o búsqueda de información con el incentivo de mejorar su puntaje. A fin de cuentas, estudian en casa previamente, lo que facilita las explicaciones y el desarrollo de la clase.

Respecto a la búsqueda de información en internet, muchos acusan a los centennials de quedarse con el primer resultado que encuentran. La contracara del multitasking y la infinita catarata de estímulos digitales con la que se enfrentan a diario es que les cuesta concentrarse, lo que algunos reconocen como un déficit de atención y otros como su modo de ser. En este sentido, una de sus mayores demandas es que la escuela les enseñe a buscar y analizar información en internet: «Es más importante que la escuela enseñe a chequear información que a adquirirla, porque googlear, googlea cualquiera» (Madre, 37). Esta práctica se asocia a la investigación, la lecto-escritura tradicional y de hipertextos.

Las estadísticas disponibles a nivel nacional indican que el acceso a la TV, la radio y los teléfonos celulares está casi universalizado. Sin embargo, es mucho menor la población que tiene acceso a una computadora en su hogar y a otros 
dispositivos digitales, y es mucho menor también el acceso de la población a internet (INDEC, 2011). Por otra parte, el uso de estas tecnologías, de la misma manera que ocurrió con otras tecnologías a lo largo de la historia, requiere ciertas habilidades y disposiciones que posibiliten a los usuarios no solo acceder a los dispositivos, sino también convertirse en usuarios expertos [...], donde la escuela adquiere un rol clave. En este nivel, la desigualdad es muy significativa. (Adrogué y Orlicki, 2020: 3)

En una línea que podríamos denominar «estímulo de la capacidad lectora crítica», Julieta Armella (2016) sugiere que los docentes incentiven a sus estudiantes a aprender a seleccionar información. Las habilidades de navegación pueden resumirse en saber encontrar materiales específicos, evaluar su credibilidad, legitimidad, precisión y utilidad, y saber interpretar y resumir los datos obtenidos. Esta competencia resulta más compleja de lo que parece, no se adquiere rápidamente y la escuela es fundamental en su estímulo y desarrollo. En la misma línea, Marina Kriscautsky (2014) e Inés Dussel (2017) advierten que los jóvenes ponen en juego otros saberes para jerarquizar y criticar la información, es decir, que necesitan de cierto volumen de lecturas y capacidad de lecto-escritura para evaluar la confiabilidad de los distintos materiales en internet. De esto se desprende que, teniendo un mayor caudal de lecturas críticas y cierto entrenamiento en desarrollar una interpretación analítica de distintos textos, podrán desarrollar un rol más activo y construir conocimiento por sí mismos.

Tal como sucede en el sistema educativo en general, la modalidad a distancia nos interpela sobre el acceso diferencial a los recursos tecnológicos, el lugar que ocupan lxs docentes en ese escenario, el rol de lxs pares y la demanda que implica para las familias, ya que esta modalidad de vínculo social mediada por las tecnologías digitales es más habitual en sectores medios, altos y de contextos urbanos. No se trata solamente de la presencia o no de dispositivos (tablets, celulares, computadoras que tengan buena conectividad a redes de internet y que permitan el acopio de múltiples archivos), sino de conocimientos para poder gestionar esos dispositivos en términos escolares para producir e interpretar materiales pedagógicos. En otras palabras, disponer de un celular no necesariamente expresa esas potencialidades, ya que frecuentemente se utilizan como dispositivo de comunicación (oral y/o escrita) en reemplazo al teléfono de línea, o bien para actividades de recreación (escuchar música, tomar fotografías o filmar videos). (Aliata et al., 2020, s/n) 
Un informe de la consultora Trendsity (2020) sostiene que el $88 \%$ de argentinos cree que tener internet domiciliaria es un servicio de necesidad. El $70 \%$ indica que no podría transitar esta cuarentena sin conexión a internet. No obstante, el $40 \%$ carece de banda ancha fija domiciliaria. Pese a esto, la mayoría asocia las tecnologías digitales a la condensación del clima de época tecno-científico, en el cual el aspiracional se despliega alrededor de la figura del «hiperalfabetizado», el experto informático-tecnológico que resulta, en tanto hacker o programador, la nueva versión erudita de un macro-lector. En este sentido, se ha generalizado la creencia de que una conexión cotidiana a internet es fundamental para estudiar y conseguir un buen trabajo. En suma, en la era de la comunicación digital permanente, ser ciudadano del mundo contemporáneo se asemeja en el imaginario a ser internauta full-time.

\section{Paradojas de la educación en pandemia}

La crisis provocada por la pandemia aceleró el proceso que venía gestándose en torno a la digitalización vertiginosa de la educación formal e informal en los distintos niveles. Esta mayor digitalización multiplica el debate sobre la calidad, eficacia, democratización y meritocracia de la educación a distancia. En este contexto, numerosos estudiantes reclaman una urgente actualización de contenidos, en particular vinculados a aspectos tecnológicos y pedagógicos, mientras que una significativa parte de docentes se quejan del rol pasivo que toman los estudiantes:

Los espacios virtuales construidos por docentes, debido al contexto de pandemia que impide las clases presenciales, podrían contar con una mayor participación de estudiantes, quienes podrían proponer sitios web para trabajar determinadas temáticas e incluso ser quienes creen material e insumos sobre las clases y los sitios. (Docente, 30, escuela privada)

A su vez, observamos que los estudiantes se quejan de cierta brecha entre los contenidos que consumen y asumen como propios -cuando están solos o entre pares-y los impartidos por el sistema educativo, que tiende a reproducir y jerarquizar el modelo enciclopédico, las fotocopias en PDF, la memorización de datos y la lectura de textos clásicos. En este marco, otro reclamo estudiantil generalizado es tener más conectividad en la escuela ("wifi para todos») y que les enseñen informática aplicada: aprender a programar, editar y usar distintos programas útiles para la vida y el trabajo. 
Pizarra digital hemos usado poco, solo cuando vamos al aula de computación, dos veces por año. Tuvimos un profesor que nos traía las compus que había funcionando. Nos poníamos en grupo y hacíamos trabajos prácticos buscando material en la compu. Aunque sea, te llama más la atención y te cambia la dinámica de copiar y escuchar hablar al profesor. Vimos documentales en geografía sobre la cuestión ambiental. También tenemos talleres artísticos de teatro, música y dibujo. Ahí también se usa la tecnología como recurso. En teatro, que es una materia curricular, vimos un par de películas. (Estudiante, 17, escuela pública)

A veces son raros los temas que se tocan: hardware, software. No me sirve, enseñame a usar programas. De primero a quinto año tenemos tecnología, informática. En tercero vimos la estructura de las computadoras, qué partes tenían. En cuarto vimos Photoshop y edición. En quinto estamos viendo Excel, ahora nos mandó un trabajo la profe. Eso sí es más útil porque lo vas a usar a lo largo de tu vida. Nos mandó una imagen de cómo tenía que quedarnos el Excel y nos fue indicando los pasos y funciones que teníamos que hacer. Está bueno. Pero quedás en lo mismo si no tenés los recursos; sin una compu que te funcione bien, no podés hacerlo. (Estudiante, 17, escuela pública)

El aislamiento obligatorio incrementa la tensión vinculada al nivel socioeconómico entre quienes cuentan con recursos informáticos y familiares a quienes consultar o pedirles ayuda, y quienes no disponen de estos medios. Una gran parte de los estudiantes tienen de una a cinco clases semanales por videollamada (Zoom, Meet o Jitsi), cuya asistencia en ocasiones es intermitente debido a problemas de conexión o inconvenientes técnicos, tanto de estudiantes como de docentes.

El estrés fueron los primeros meses de pandemia. Ahora ya te manejo todo: uso de plataformas para hacer clases por videollamada (Meet, Zoom), hacer presentaciones de PowerPoint desde ambas aplicaciones, grabar las clases y mandárselas como enlaces de YouTube, la app CamScanner para escanear con el celular. Me costó la plataforma educativa del INFOD [Instituto Nacional de Formación Docente dependiente del Ministerio de Educación de Argentina] porque no es nada intuitiva. También uso Moodle, grupos de WhatsApp donde mando videos de YouTube, posts de Instagram, capturas de pantalla. Mucho correo electrónico con adjuntos y enlaces a mis distintos Drive. Me hice fanática de los formularios Google, los uso para todo, exámenes... Ahora preparé una encuesta para la jornada sobre prevención de violencia de género. (Docente, 56, escuela pública) 
En el sur de la Ciudad de Buenos Aires, se calcula que un $70 \%$ de estudiantes carece de conectividad a internet en sus hogares, así como de recursos para comprar datos móviles en su teléfono de manera regular. Muchos comparten los datos móviles con otros miembros de su familia. Por ejemplo, comparten un teléfono con datos entre varios hermanos y con los padres. En este contexto, resolver tareas escolares de modo online se torna más dificultoso que para estudiantes con conectividad continua: «En muchos casos hay un celular por familia y tienen que laburar el padre, la madre, los hijos tienen que hacer la tarea» (estudiante, 18, escuela pública).

La encuesta COVID de UNICEF (2020) señala que la mayoría de niños y adolescentes divide su tiempo entre las tareas escolares, conversar con amistades, colaborar con tareas domésticas, usar redes sociales y entretenerse con videojuegos. Alrededor del $80 \%$ recibe tareas escolares; sin embargo, el $30 \%$ señala que no tiene feedback docente. Además, el $20 \%$ no cuenta con acceso a internet y el $40 \%$ no dispone de computadora, ni tablet. Respecto a la situación emocional de adolescentes, el $20 \%$ se siente asustado, el $15 \%$, angustiado, y el $5 \%$, deprimido.

En la población escolarizada se nota más cansancio, desánimo, critican que esto no es la escuela, tienen pocas ganas de participar. Los más motivados cuentan con ámbitos familiares que les permiten tener rutinas educativas. En mi caso, donde somos dos adultos docentes y tres hijos, es casi imposible, porque hay clases y trabajos en paralelo. Esas situaciones generan más discontinuidades. (Docente, 44, escuela pública)

Una investigación de la Coordinadora de estudiantes secundarios y familias por la escuela pública (2020) señala que en la Ciudad de Buenos Aires la gran mayoría de estudiantes posee e-mail, pero uno de cada cuatro no tiene computadora y uno de cada diez no cuenta con wifi o posee un servicio intermitente. Siete de cada diez tienen datos en su teléfono móvil. Más de la mitad no conoce un servicio técnico para su netbook del Plan Sarmiento o Conectar Igualdad y alrededor de un cuarto necesita reparación.

En el colegio hay bastantes computadoras del Conectar Igualdad, pero la mayoría están bloqueadas o no funcionan. Fue un reclamo que también dimos en pandemia. En el turno tarde tenemos $50 \%$ de los pibes desconectados. Intentamos arreglar esas compus para hacérselas llegar a esos pibes. Muy difícil. Tenemos sala de computación que ahí está, se usa poco, en alguna que otra materia. No hay buen wifi ni buenos recursos. Es difícil usar la tecnología. Desde el centro de estu- 
diantes también estamos a favor de que toda política de inclusión tecnológica se haga efectiva y llegue lo mejor posible, en especial para los que más las necesitan, los estudiantes de menores recursos. (Estudiante, 18, escuela pública)

Además, dos de cada diez estudiantes no pudieron ser contactados por sus escuelas durante la pandemia y la mitad indica que no pudo entregar todos los trabajos prácticos pedidos. El $75 \%$ no tuvo clases mediante videollamada o formatos sincrónicos, y un tercio no puede contactarse con sus docentes de modo regular.

Más que nada necesitamos clases, aunque sea virtuales, con las materias que son exactas: Matemática, Física, Química, Biología. Yo sigo la orientación biológica y hay cuestiones de química y esas cosas que son imposibles de explicar sin un video o una explicación directa del profe. Vos podés googlear, pero no tenés forma de saber si lo que estás poniendo es correcto. Tuvimos una materia en la que teníamos que hacer trabajo en grupo y teníamos que hacer videollamadas con los compañeros. Está bueno, pero es difícil. Un par de profesores grabaron algunos videos explicando algunos temas. (Estudiante, 16, escuela pública)

En cuanto a las diferencias entre escuelas públicas y privadas, si bien el $97 \%$ de nuestra muestra tiene internet, en las privadas la proporción de estudiantes con acceso a dispositivos tecnológicos y a internet es mayor que en las públicas. En particular, la diferencia se evidencia con las públicas que poseen una mayoritaria población de sectores populares.

Las grandes diferencias que se dieron son por las desigualdades de base. La población que asiste a escuelas privadas suele tener un acceso a tecnología y conectividad casi del $100 \%$. Entonces se pudo pensar una cuestión sincrónica más continua. En la escuela pública muchos estudiantes tienen dificultad de contacto por la carencia de equipos y conectividad. Además, la escuela pública ha tenido que dar cuenta de cuestiones alimentarias y de otras cuestiones de necesidad social, vinculadas a la falta de trabajo y al aislamiento. Violencias intrafamiliares, situaciones anímicas, que también pasaron en poblaciones de escuelas privadas, por supuesto. Pero en las públicas tuvo mayor peso la cuestión económica. Muchos estudiantes, además, se fueron a vivir a sus lugares de origen en el interior y perdieron contacto con la escuela. (Docente, 47 años, escuela pública)

Las escuelas privadas parecen haberse adaptado mejor al nuevo contexto, quizás por contar con una población menos golpeada por la crisis socioeconómica. 
Con una relación más fluida con las tecnologías, evidencian mayor regularidad en horas de cursada y en actividades que parecen concentrarse en lo académico:

Suelo tener clases entre las 8.20 y 17.30. En promedio, tengo tres o cuatro horas de clase por día. Más allá de las clases online por Zoom, estoy haciendo unos trabajos prácticos que hay que entregar mediante el campus virtual. Utilizan eso para las valorizaciones de lo académico. Después, para la parte psicopedagógica, digamos, se utiliza la presencia y la participación en las clases virtuales. También estoy haciendo un reflection paper para un curso extracurricular, que es una síntesis de todo lo que aprendí en las clases, y también estoy preparando un modelo legislativo para noviembre, que es otra actividad extracurricular. De todos modos, siempre la tecnología estuvo muy presente en nosotros, así que el cambio no fue tan drástico. Pese a esto, aunque sé que somos privilegiados, nuestra calidad educativa disminuyó. Imagino que menos que en escuelas con menos recursos, pero también disminuyó. (Estudiante, 17 años, escuela privada)

La regularidad de clases por videollamadas también se observa en escuelas católicas, que han hecho un convenio con la editorial Santillana para utilizar la plataforma E-stela en sus clases a distancia. Por su parte, algunas escuelas públicas utilizan la plataforma Edmodo y dan clases por Zoom, con la limitación de los cuarenta minutos (de todos modos, pueden reiniciar la sesión con el mismo link). Más allá de las reiteradas críticas por la escasez de clases sincrónicas, tanto en nivel inicial como secundario, muchos estudiantes reivindican el rol docente, comprometido y empático con la situación.

Tuvimos muy pocas clases por videollamada. Desde el centro de estudiantes reclamamos para que los profes nos den clases, porque solo mandaban PDF con trabajos prácticos y fuentes de donde sacar la información. También muchos profesores y autoridades están comprometidos con la cuestión social. Hay docentes que no tenían compu y se las tenían que arreglar. (Estudiante, 17, escuela pública)

Las actividades fueron fluyendo y variando entre lo que cada institución pudo ir armando. Quienes trabajamos con poblaciones vulnerables fuimos buscando los recursos más adecuados. En muchos casos, tareas en papel, con la entrega quincenal los días en que se entrega comida y que eso tenga una devolución. Funcionó mucho el WhatsApp porque celular tienen prácticamente todos y computadora no tanto. Aunque había que tener datos. Y compartir dispositivos entre distintos miembros de la familia termina haciendo que el docente tenga actividad casi veinticuatro horas. Porque está el pibe que contesta a las doce de la noche, dado que es cuando tiene acceso al teléfono. (Docente, 43 , escuela pública) 
La encuesta que realizamos, con una población mayor de sectores medios que otras encuestas mencionadas, arroja algunos datos diferentes: el $75 \%$ de los estudiantes recibe consignas o actividades en aulas virtuales, además de videos de sus docentes donde se explican temas curriculares. Solo el $25 \%$ recibe consignas por e-mail o WhatsApp. Nueve de cada diez se contactan todas las semanas con docentes y compañeros. El $58 \%$ usa una notebook o netbook para realizar sus tareas escolares, el $25 \%$ utiliza una PC de escritorio y el $12 \%$ su teléfono.

Además, el $70 \%$ sostiene que ha aprendido menos que cuando iba a clases presenciales y el $75 \%$ quisiera que, cuando se normalice la situación, las clases sean iguales a como eran antes de la pandemia. Sin embargo, el $20 \%$ quisiera que siga habiendo más clases virtuales y menos presenciales. Estos datos no terminan de mostrar ciertas subjetividades del fenómeno, que sí han salido a la luz en las entrevistas que realizamos. Con la pandemia, muchos estudiantes extrañan el contacto cotidiano con compañeros, docentes y amistades, la sociabilidad del aula y los recreos, abrazarse o simplemente sentir la presencia del otro. También extrañan la biblioteca y las actividades de talleres o laboratorio.

Se extraña el contacto. Ser quince o veinte pibes en un aula. Extraño el debate con profesores y compañeros y los espacios de reflexión como el taller de la memoria y la interacción con el equipo ESI. Hay muchas actividades que hacen que uno se vaya encariñando más con el colegio a lo largo de los años. Esas cosas son las que más se extrañan. También los recreos y ranchar [juntarse] con amigos. (Estudiante, 17, escuela pública)

Prefiero ir a cursar y el intercambio cara a cara, pero es lo que hay. Ahora hay que cursar a distancia o nada, no queda otra. Pero a distancia se retiene menos y tomo menos apuntes. Tenemos muchos estímulos frente a la compu: juegos, textos, chats. No está la atención centralizada y no hay conexión real ni debates. Además de que muchos docentes no tienen los recursos adecuados para clases virtuales; por ejemplo, no tienen materiales o pizarrón. (Estudiante, 17, escuela privada)

Esta coyuntura, sin duda atípica y de emergencia, plantea nuevos interrogantes sobre cómo mantener una enseñanza inclusiva y de calidad, sobre todo en el sistema público, cuya función democratizadora ha quedado ciertamente restringida. El rol compensatorio de las escuelas en la difusión de conocimiento, la ampliación de ciudadanía y la socialización cultural y tecnológica se ha visto disminuido durante la pandemia, en particular en sectores populares urbanos, suburbanos y rurales. 
Además, ante la crisis socioeconómica, numerosos estudiantes tuvieron desperfectos en sus dispositivos que no pudieron reparar, o debieron salir a trabajar en lo que encontraron para ayudar a sus familias, en muchos casos en locales de comida rápida o de repartidores mediante las conocidas aplicaciones. Algunos deben compartir el dispositivo con alguien que también lo necesita, o cuidar a algún familiar enfermo con COVID. En todo caso, a muchos se les complica estar presentes en las clases sincrónicas por videollamadas, 0 articular las distintas actividades que impone el nuevo contexto.

\section{Subjetividades en conflicto}

La dinámica escolar tiene doscientos años. Ante la interpelación a reinventarse, autoridades y docentes no niegan la centralidad de las tecnologías, aunque aún no sepan cómo lograr una implementación integral y eficaz. En este marco, se torna necesario interrogarnos acerca del conocimiento puesto en juego en las clases, en las currículas y actividades online y, en particular, qué habilidades necesitan los adolescentes para seleccionar información útil en internet. También debemos pensar cómo será la vuelta presencial a las clases y cuál será el rol de las tecnologías en ese contexto.

Los países han optado por distintas estrategias para convertir de manera temporal y acelerada sus sistemas educativos presenciales en virtuales. Esto ha revelado la escasez de modelos pedagógicos y de preparación de contenidos, así como las desigualdades en torno a los recursos tecnológicos de distintos países, provincias y familias. Según el CIPPEC (2020), la mitad de los diez millones de estudiantes en Argentina tienen recursos insuficientes para desarrollarse plenamente; en especial, la mitad de adolescentes de sectores populares no cuenta con una computadora. Dentro de un sistema educativo con desiguales recursos tecnológicos y capacidades de gestión, varias provincias han elaborado y entregado materiales complementarios, como cuadernillos impresos, programas de TV y radio, portales educativos y plataformas.

Hubo que inventar la continuidad pedagógica en la virtualidad. Es muy difícil planificar, estás siempre improvisando, y las decisiones institucionales van cambiando la dinámica. Hubo un primer momento de ansiedad de todos; ahora se llegó a cierta estabilidad, pese a estar acomodando las reuniones que surgen. (Docente, 38, escuela privada)

En un primer momento se confió en que la temporalidad de la pandemia iba a ser corta y se «descansó» en que esto era un tiempo, e iba a pasar, entonces se les exigió menos a los estudiantes. Cuando se vio que esto iba a durar, se jugaron 
varias cosas. En primer lugar, las exigencias burocráticas. En segundo lugar, siempre está presente la idea de que estamos en un tiempo perdido. En tercer lugar, muchos docentes empezaron a exigir como si estuviesen en la escuela. Con las salvedades del caso, pero sin contar que esa exigencia no es posible de cubrir sin el acompañamiento de un profesional docente. Entonces la exigencia empezó a darse sin contar que no todo padre y madre está en condiciones de acompañar estos procesos, por diferentes motivos. Desde la conectividad y el equipamiento hasta que no todos tienen que saber cómo dividir en matemáticas. (Docente, 43 años, escuela pública)

Respecto a la nueva modalidad educativa, se propone hablar de educación a distancia, no virtual. Entre sus ventajas, permite a docentes y estudiantes vincularse desde otro lugar, desarrollando una cultura digital. Asimismo, resulta útil para trabajar de modo ubicuo, dado que ayuda a articular horarios y posibilita cursar a quienes viven lejos o disponen de tiempos acotados. Además, permite centralizar el trabajo en un mismo sitio e incorporar con mayor facilidad recursos multimedia a las clases expositivas, como pasar videos, imágenes o diapositivas, o darlos como material complementario.

Las desventajas son el menor feedback inmediato de estudiantes (aunque puedan preguntar o comentar por chat o mensajes), el insuficiente dominio de habilidades informáticas y la baja motivación. Si en la enseñanza presencial es difícil estimular actitudes y emociones positivas que mejoren el rendimiento, a distancia esta tendencia se incrementa. A su vez, existe una mayor dispersión de los estudiantes, así como una sobrecarga de trabajo docente. Los correos y mensajes de WhatsApp a cualquier hora generan estrés y burnout en estudiantes $y$, en especial, en docentes.

Los docentes también entienden que es un tiempo distinto y son los que más sostienen esto. Por eso su negativa a volver a las aulas. Muchos estudiantes han pedido a sus docentes que estén presentes de algún modo. En ese encuentro estudiante-docente se da la interpelación ética y el acompañamiento, que es siempre inédito. Ninguna estructura de aprendizaje a distancia va a modificar esa situación. Es en el encuentro con la mirada y la corporalidad del otro donde se construye humanidad, donde se otorgan múltiples sentidos a la realidad, donde lo poético se torna político. (Docente, 44, escuela pública)

¿Cómo lograr el acceso democrático a las tecnologías? El desafío de la educación argentina, referente internacional en cuanto a su extendida gratuidad, masividad y calidad, continúa siendo garantizar el derecho a la educación y la 
continuidad pedagógica. Una respuesta son las aulas mediadas por tecnologías: una clase expositiva teórica quizás no termine de aprovechar los recursos disponibles del mejor modo, dado que todos estamos atravesados por la tecnología. Pero que sea todo videoconferencia tampoco es la forma; muchos docentes sugieren que es útil un documento base que guíe, y complementarlo con tutoriales y otros recursos. También aconsejan que los estudiantes lleven un portfolio de sus tareas y actividades en cada materia.

Los centros de estudiantes continúan difundiendo informaciones y actividades mediante redes sociales y mensajería digital. Sus críticas, como hemos visto, no apuntan tanto a docentes sino al bajo presupuesto gubernamental, en particular respecto a los salarios, el mantenimiento edilicio, el equipamiento tecnológico y las dificultades de accesibilidad de una parte del estudiantado.

Tratamos de estar activos todo el tiempo porque es necesario. Que los pibes sepan que estamos ahí. También armamos actividades en conjunto con profesores, docentes y cooperadora. Nos agarramos de lo que podemos. Casi toda la comunicación la hacemos por redes sociales. Armamos un ciclo de debates por videollamadas. Tuvimos vivos de Instagram, subimos videos. (Estudiante, 18, escuela pública)

Los gobiernos han desplegado políticas orientadas a asegurar la continuidad pedagógica y a sostener el vínculo con las familias. Los países que comenzaron la reapertura de escuelas coinciden en múltiples criterios: escuelas seguras, retorno gradual, decisiones contextualizadas con participación local y sostenimiento de estrategias presenciales y a distancia.

Llegando al fin de este 2020 atípico, se plantea otro problema: el de evaluación y promoción de cada asignatura, en especial en los últimos años de cada nivel, en un momento de excesiva ansiedad y crisis económica-social, con miles de estudiantes viviendo en la marginalidad y docentes bajo la línea de pobreza. En este contexto, algunos directivos presionan a sus docentes para realizar videoconferencias diarias por Zoom o crear videos explicativos, o continúan deteniéndose en formalidades y burocracias.

No creo que haya que hablar de año perdido. La mayoría de docentes pudo acompañar durante el año a los estudiantes. Aunque sea un poco. Creo que en estos momentos no es lo más relevante el contenido sino qué les queda de toda esta experiencia. Lo que tiene que ver con lo biográfico, con cómo lo están llevando. (Docente, 40, escuela pública)

¿Qué es lo importante en esta coyuntura? ¿Mostrar que podemos continuar «transmitiendo» contenidos? Como muestra un meme muy difundido con docentes 
como músicos del Titanic que continúan tocando a pesar del hundimiento inminente, es importante no perder el año escolar y continuar el proceso de enseñanza. Esto no significa llenar de trabajos prácticos a estudiantes que también se están adaptando a una nueva realidad y tienen incertidumbre. El día de entrega de bolsones de alimentos continúa siendo el momento donde las familias se acercan y manifiestan sus dificultades. Varios mencionan que sus hijes están deprimidos o desbordados. Es momento de buscar estrategias que garanticen una educación inclusiva y permitan la continuidad del vínculo entre docentes y estudiantes, esa necesaria socialización secundaria. El desafío principal consiste en garantizar el derecho a la educación. De no hacerlo, estaremos siendo cómplices de profundizar las desigualdades sociales. (Docente, 28, escuela pública)

Si bien las familias deben articular los tiempos escolares con los laborales, esta sobrecarga recae en particular en las mujeres. Dado que los menores de quince años no suelen ocuparse de sus tareas sin distracciones ni resistencias, padres $y$, en especial, madres se ven obligadas a disponer de entre una y cuatro horas diarias para asegurar ese proceso. Este contexto subraya las diferencias de clase: así, resultan favorecidos quienes cuentan con familiares con mayor formación académica y más tiempo libre. Noelia Enriz (2020) señala:

El vínculo entre escuelas y familias cambió muy drásticamente. En general, no se depositaba en la familia la construcción del conocimiento escolar de los niños y las niñas. De eso se encargaban las instituciones, mientras que se esperaba que la familia aportara otros conocimientos. Pero en este escenario se pide a la familia que fortalezca la continuidad en la formación pedagógica.

Esta sobrecarga de tareas afecta también a los casi 900 mil docentes de nivel inicial, primario y secundario de Argentina. En este escenario, la enseñanza remota de emergencia se improvisa, tratando de trasladar la experiencia de aprendizaje del aula al ciberespacio. A su vez, se plantea el debate sobre cómo planificar la vuelta a las clases presenciales.

Volver a clases no es posible al menos por varios meses. Hay amagues de regreso a clases que no es volver a clases, es otra cosa. Suponiendo vacunación e inmunización generalizada, la institución y el hecho educativo tienen que transformarse. Se va a volver con miedo de muchos docentes y estudiantes. Hay que poder trabajar lo biográfico y las sensaciones que nos van a quedar en el cuerpo. Un regreso a clases va a tener que ser con mucho cuidado, porque va a haber muchas sensaciones encontradas en el hecho educativo, como can- 
sancio, miedo y desacostumbramiento. Sin los recursos de higiene y cuidado necesarios, no se puede volver. (Docente, 43 años, escuela pública)

Si se aspira a una sociedad más igualitaria, las políticas educativas por venir deberán mitigar la profundización de las brechas en el acceso al conocimiento, un bien estratégico en el siglo XXI y un derecho inalienable para todos. Ante la virtualización forzada de las formas educativas, el futuro de las escuelas parece acelerarse en dirección a una educación virtual o al menos semipresencial, con encuentros presenciales esporádicos, que de seguro cambiarán en cuanto a sus disposiciones tradicionales. Esta modalidad no soslaya el aspecto humano propio del aula presencial, esa química única que se genera en los encuentros cara a cara. En la educación a distancia se produce una dinámica singular, que no es igual a la presencial.

\section{Reflexiones finales}

La tecnología es un hecho, una realidad omnipresente que llegó para quedarse. Ahora con más premura, se plantea la discusión sobre qué hacer. Algunos sugieren que una mejora sería institucionalizar la gamificación. Sus apóstoles aseguran que es necesario introducir juegos en el aprendizaje para salir de la crisis de sentido y disminuir la brecha de intereses entre el ethos adolescente y el sistema educativo. Lo que parece vislumbrarse es un modelo híbrido, que articule lo presencial con lo virtual y lo digital con lo analógico, que combine tecnologías milenarias como el cuaderno, el libro y el lápiz con otras que siguen actualizándose, como internet y las redes sociales.

La pregunta es cómo pensar, leer y estudiar juntos en el siglo XXI. ¿Cómo hacerlo a distancia, cómo adaptar las metas de aprendizaje a contextos determinados? ¿De qué modo podemos lograr que la educación virtual no recaiga sobre padres y madres, sobrecargados de tareas? ¿Cómo pensamos una defensa de la educación pública antes de que la pandemia se la cobre como víctima? Además, ¿cómo evaluar a distancia y disminuir la deserción estudiantil? Algunos padres se quejan de que sus niños no aprenden contenidos. Por el contrario, otros opinan que en contextos de crisis la escuela pública no debe ser contenidista, sino un espacio de contención y encuentro con el otro: reparto de bolsones, colectas y actividades sociales realizadas por cooperadoras y centros de estudiantes, y chats sumamente activos de la comunidad educativa.

Ya no hay excusas ni límites horarios, dado que tanto jóvenes como adultos utilizan todo el día dispositivos digitales para comunicarse, estudiar y trabajar, generando un continuum online-offline cada más intenso. Las tecnologías no 
son externas a nosotros: somos también pantallas, imágenes digitales, plataformas de videollamadas, chats y redes sociales.

Entonces, ¿cómo desmitificar prenociones sobre los estudiantes y estimular su capacidad de reflexión, guiándolos para que hagan usos lúcidos y pedagógicos de las tecnologías de información y comunicación? ¿Cómo entusiasmarlos con las tecnologías milenarias del libro y el texto escrito? ¿Cómo salir de la enseñanza memorística, contenidista y burocrática sin caer en los «espejitos de colores» que anuncian la inevitabilidad de la tecnologización superflua que promueven los algoritmos? ¿Cómo acercar posiciones entre estos mundos distantes y fortalecer el vínculo pedagógico así como el espacio de la escuela como lugar de encuentro intra e intergeneracional?

En la era de la comunicación permanente, donde cada vez es más dificultoso establecer un límite entre el adentro y el afuera, ¿cuáles son los modos más adecuados de generar pensamiento y aprendizaje significativo desde la escuela? ¿Cómo mantener vigente la propuesta de la escuela como espacio igualitario de posible ascenso social y de investigación sobre las distintas áreas de conocimiento del mundo? ¿La motivacional gamificación y la tecnologización que se anuncian como inevitables banalizan el saber y empobrecen la educación? ¿Cómo reconfigurar el contrato social escolar con un nuevo pacto entre estudiantes y adultos? ¿Qué métodos pedagógicos son más estratégicos para la construcción de conocimiento específico? ¿Qué contenidos acerca de las ciencias y lo público son fundamentales en la escuela y cuáles deberían actualizarse? Nadie tiene respuestas claras, pero es importante pensar modelos híbridos que combinen tecnologías analógicas y digitales del mejor modo posible, así como habilitar el diálogo entre los distintos actores contemporáneos para encontrar nuevos consensos y formas de construir conocimiento en el espacio común escolar.

Numerosos docentes y estudiantes coinciden en la necesidad de actualizar el paradigma individualista y meritocrático para hacerlo dialogar con un paradigma del conocimiento abierto, ubicuo y colectivo sin perder calidad. Más en este contexto, la comunidad educativa -docentes, directivos, referentes, cooperadoras, centros de estudiantes y grupos de pares- articula coordenadas fundamentales en torno a la construcción de ciudadanía, los riesgos y usos expertos de las tecnologías digitales, los derechos y obligaciones que implica vivir en sociedad, las identidades juveniles y la empatía sobre las diversas formas de vida. 


\section{Nota}

1. Si bien acompañamos las luchas por la igualdad de derechos y prácticas que reivindican los feminismos, en muchos casos aquí optamos por el universal masculino por una cuestión de síntesis y legibilidad,

\section{Referencias bibliográficas}

ADROGUÉ, C. y Orlicki, M. (2020). Acceso y uso de las tecnologías de la información y comunicación (TIC) en la escuela secundaria en diferentes contextos socioeconómicos en Argentina. Praxis Educativa, 24 (3), 1-12. DOI: 10.19137/praxiseducativa-2020-240308

ALIATA, S. et al. (2020). Informe: La Educación Intercultural Bilingüe en Chaco y Misiones frente a la pandemia del CoVID-19. Disponible en: https://www.conicet.gov.ar/ wp-content/uploads/Informe-EIB-en-contexto-COVID-19.pdf

ARMELLA, J. (2016). Hacer docencia en tiempos digitales. Un estudio socio-pedagógico en escuelas secundarias públicas emplazadas en contextos de pobreza urbana. Estudios Pedagógicos, 42 (3), 49-67. DOI: 10.4067/S0718-07052016000400003

BENITEZ LARGHI, S. (2020). La construcción de habilidades digitales estudiantiles en torno al Programa Conectar Igualdad. Ciencia, Docencia y Tecnología, 31, 131-154. DOI: 10.33255/3160/581

BURBULES, N. (2012). El aprendizaje ubicuo y el futuro de la enseñanza. Encounters/Encuentros / Rencontres on education, 13, 3-14.

CIPPEC (2020). ¿Cuál fue la respuesta del sistema educativo argentino ante la pan- sin desconocer las implicancias del lenguaje inclusivo y respetuoso por las diversidades, que a veces se utiliza para visibilizar estas tensiones. « VOLVER

demia? Disponible en: https://www.cippec org/textual/cual-fue-la-respuesta-del-sistema-educativo-argentino-ante-la-pandemia COORDINADORA DE ESTUDIANTES SECUNDARIOS Y FAMILIAS POR LA ESCUELA PÚBLICA (2020). Investigación sobre educación durante la pandemia. Disponible en: http:// www.psocialista.org/educacion-virtual-como-la-perciben-les-estudiantes

DUSSEL, I. (2017). Las tecnologías digitales y la escuela: ¿tsunami, revolución o más de lo mismo? En Montes, N. (ed.), Educación y TIC. De las políticas a las aulas (pp. 95-122). Buenos Aires: Eudeba.

ENRIZ, N. y otros (2020). Cómo afecta la pandemia de COVID-19 a la educación en comunidades indígenas. Disponible en: https:// www.conicet.gov.ar/como-afecta-la-pandemia-de-covid-19-a-la-educacion-en-comunidades-indigenas

GVIRTZ, S. y Larrondo, M. (2007). Notas sobre la escolarización de la cultura material. Celulares y computadoras en la escuela de hoy. Teias, 8 (15-16), 1-10.

HERNÁNDEZ-HORTA, I.; Monroy-Reza, A. y Jiménez-García, M. (2018). Aprendizaje mediante juegos basados en principios de gamificación en instituciones de educación 
superior. Formación Universitaria, 11 (5), 31 40. DOI: $10.4067 / 50718-50062018000500031$ HOLGUín, F.; Holguín, E. y García, N. (2020). Gamificacion de la enseñanza de las matemáticas: una revisión sistemática. Telos: Revista de Estudios Interdisciplinarios en Ciencias Sociales, 22 (1), 62-75. DOI: 10.14201/teri.20625 ORTIZ-COLÓN, A.; Jordán, J. y Agredal, M. (2018). Gamificación en educación: una panorámica sobre el estado de la cuestión. Educação e Pesquisa, 44. DOI: 10.1590/s1678-4634201844173773

KRISCAUTSKY, M. (2014). Seleccionar información en Internet. Problemas y soluciones de los nuevos lectores ante la confiabilidad de las fuentes digitales de información. Tesis doctoral, DIE-CINVESTAV.
TRENSITY (2020). Informe sobre brecha digital. Disponible en: https://www.trendsity. com/brecha-digital-y-las-nuevas-desigualdades-que-se-incrementaron-como-consecuencia-de-la-pandemia

Tófalo, A. (2016). Aprender 2016. Acceso y uso de TICS en estudiantes y docentes. Disponible en: https://www.argentina.gob.ar/ sites/default/files/acceso y uso de tic en estudiantes y docentes.pdf

UNICEF (2020). Encuesta COVID. Disponible en: https://www.unicef.org/argentina/media/7866/file

ZEPEDA-HERNÁNDEZ, S.; Abascal-Mena, R. y López-Ornelas, E. (2016). Integración de gamificación y aprendizaje activo en el aula. Ra Ximhai, 12 (6), 315-325. 